\title{
Immunostaining of Voltage-Gated Ion Channels in Cell Lines and Neurons - Key Concepts and Potential Pitfalls
}

\author{
Elke Bocksteins ${ }^{1,2,}$, , Andrew J. Shepherd ${ }^{2,}$, \\ Durga P. Mohapatra ${ }^{2}$ and Dirk J. Snyders ${ }^{1}$ \\ ${ }^{1}$ Department of Biomedical Sciences, University of Antwerp, Antwerp; \\ ${ }^{2}$ Department of Pharmacology, University of Iowa Carver \\ College of Medicine, Iowa City, Iowa, \\ ${ }^{1}$ Belgium; \\ ${ }^{2} U S A$
}

\section{Introduction}

Widely acknowledged to be the first person to make detailed studies of microscopic objects, the pioneering work of Antonie van Leeuwenhoek (1632-1723) provided the first glimpse of neurons when he observed sections of bovine optic nerves (van Zuylen, 1981). It was over a century later when the Italian scientist Camillo Golgi (1843-1926) developed la reazione nera ('the black reaction'), later dubbed the Golgi stain or Golgi method, in 1873. This approach revealed a hitherto unseen world, one brought to light in stunning fashion in the decades that followed by Santiago Ramón y Cajal (1852-1934), who refined Golgi's techniques and published numerous articles detailing the fine structure of the nervous system (Ramón y Cajal, 1995). The inescapable conclusion of this work - that the nervous system is composed of discrete cellular units, or neurons, that communicate with one another in a vast network came to be known as 'the neuron doctrine.' It is from these initial findings that the sophisticated techniques available to today's scientists are descended.

One fundamental technical aspect of Ramón y Cajal's work still holds true for many contemporary techniques; the fine structure of tissues and cells must be stabilized, or 'fixed,' before any further processing or visualization can be carried out. Fixation is a crucial step in staining cells or tissues of any type. This also applies to immunocytochemistry (ICC) - the process of labeling proteins within cells and tissues with the use of specific antibodies. Despite being initially restricted to purified serum samples of ill-defined specificity, the possibilities of this technique were immediately apparent. Provided a specific antibody is available, it is possible to visualize almost any protein within the cell.

The development of the hybridoma technique to produce monoclonal antibodies against specific proteins or a specific amino acid sequence therein spurred a great increase in the practicality and popularity of immunostaining; theoretically limitless quantities of

* Both authors contributed equally to this work 
antibodies of identical specificity could be generated using cell culture. This has doubtlessly accelerated the rate of discovery across all biomedical science disciplines. The information that can be gleaned from immunostaining is not restricted merely to whether a protein of interest is present within a given cell or tissue region. In principle, almost all of the processes that a protein goes through during its lifetime can be explored by ICC with the use of antibodies. This includes changes in the sub-cellular localization of the protein, developmental or pathological changes in expression and/or localization patterns, association or dissociation with other proteins, even post-translational modifications such as glycosylation and phosphorylation, as well as degradation at the end of a protein's life (Misonou et al., 2006; Ogawa et al., 2008; Yus-Nájera et al., 2003).

A yet more recent development was the exploitation of fluorescent proteins, which, when 'tagged' onto any protein of interest, enable the visualization of proteins within live cells. This enabled the dynamics and the temporal characteristics of biological processes to be scrutinized like never before, and shed more light on the processes that enable cells such as neurons to establish and maintain homeostasis. Such approaches can be (and often are) used in conjunction with conventional immunostaining, both techniques complementing one another. The unique properties of fluorescent proteins have more recently been harnessed in another way, in order to explore associations between proteins at a truly molecular level. Only when two proteins with appropriate fluorescent protein tags are in extremely close proximity to one another can the process of fluorescent resonance energy transfer (FRET) occur, a process that today's scientists exploit in order to explore protein-protein interactions.

These techniques have allowed us to peer deeper into the complexities of cells than ever before, and still doubtlessly have a great deal to tell us. It is these techniques, their optimization, applications and limitations, which we intend to describe here by focusing on ion channel proteins expressed in cell lines and neurons as our principal examples. Ion channels are a functionally diverse group of proteins with a multitude of closely-related subfamily members. Furthermore, the extensive control over subcellular localization, protein-protein interaction and post-translational modifications these proteins undergo means that they represent both the difficulties and fascinating insights that ICC has to offer.

\section{Cell fixation}

It is self-evident that one of the key aims of ICC is to label subcellular components in a way that most closely reflects their native confirmation within the cell. This enables investigators to make judgments based on their data that are likely to be in accordance with cells and tissues in their live state. This means that all metabolic processes must be terminated as quickly as possible, whilst preserving the morphology of cells and organelles, and the distribution of proteins therein. However, fixation that is too extensive may begin to alter the structure of proteins from their native confirmation so significantly that antibodies are no longer able to bind to their target sequence in the antigen/protein (epitope), resulting in decreased staining intensity and possibly an increase in the background 'noise' of the stain. On the other hand, incomplete fixation will not halt proteolytic and other enzymatic and metabolic processes sufficiently quickly. This can also reduce staining intensity and introduce abnormal staining patterns or fixation artifacts (Spector \& Goldman, 2006). Of the main fixatives generally employed in ICC (glutaraldehyde, paraformaldehyde, 
methanol/acetone), paraformaldehyde is the most widely used, since it provides a good balance of thorough and rapid fixation of tissue/cells to preserve cell organelle morphology and the target epitope(s).

Glutaraldehyde is usually employed in electron microscopy studies because of its ability to preserve ultrastructural detail. However, the slow rate of cellular penetration and the extensive cross-linking that results from glutaraldehyde fixation make it a poor choice for most ICC studies, since this can impede antibody penetration and binding, thereby reducing specific signal and increasing background fluorescence.

Much more rapid fixation is possible with the use of cold acetone or methanol, and as a result they are employed more frequently in ICC than glutaraldehyde. However, they still present several potential problems for ICC studies. Methanol treatment leads to precipitation of proteins, which can disrupt the localization and/or detectability of certain antigens, and the permeabilization of cells that results from the solubilization of lipids may also result in the loss of more soluble antigens. Therefore, acetone or methanol fixation is usually employed only when rapid fixation and simultaneous permeabilization of cells is required, or for studies on particularly resilient antigens (e.g. the actin cytoskeleton, microtubules, intermediate filament networks (Spector \& Goldman, 2006)).

Paraformaldehyde (or, to be more accurate, simply 'formaldehyde,' once present in its monomeric form in solution) is less effective than glutaraldehyde at cross-linking proteins by forming methylene bridges, meaning that while fixation and ultrastructural preservation aren't as robust as with glutaraldehyde, antigenicity is more likely to be maintained. Like glutaraldehyde, paraformaldehyde does not permeabilize cells, meaning that, unless surface or extracellular antigens are being detected, subsequent permeabilization will be necessary. It is also for this reason that preparing fresh solutions of formaldehyde from paraformaldehyde is recommended, so that the methanol that is often present in many commercially available formaldehyde solutions does not inadvertently permeabilize the cells. For fixation of cells, formaldehyde is typically used at $3-4 \%$ in phosphate-buffered saline, $\mathrm{pH} 7.4$, and applied at room temperature for 15 minutes, or at $4^{\circ} \mathrm{C}$ for 30 minutes. The water in which the paraformaldehyde is dissolved must first be heated to approximately $60^{\circ} \mathrm{C}$ and subsequently brought to alkaline $\mathrm{pH}$ (approximately 10.5) for the paraformaldehyde to dissolve. Once the components of the phosphate buffer have been added, the $\mathrm{pH}$ must then be adjusted to 7.4 with hydrochloric acid. Opinions vary regarding the shelf life of formaldehyde prepared in this way; some generate small batches that are used within 24 hours, others generate larger quantities that are stored at $4^{\circ} \mathrm{C}$ for several months (Williams, 1997).

Several additives may also be included in the formaldehyde solution that can better preserve cell structure, the inclusion of $4 \%$ sucrose being a prime example. It is thought that the inclusion of a non-electrolyte such as sucrose inhibits the extraction of intracellular components during fixation, a factor that can improve staining quality, particularly for membrane proteins, and especially in cells such as neurons, with a large surface area-tovolume ratio. Similar effects have also been reported with the inclusion of $1-3 \mathrm{mM} \mathrm{CaCl}$ and/or $\mathrm{MgCl}_{2}$ in the fixative.

If the cross-linking that formaldehyde introduces does preclude the binding of antibodies to their target, some cross-links can be broken, restoring more of the native conformation to 
cellular structures. Such processes are referred to as antigen retrieval, and are mainly enzyme or heat-mediated. Incubation of specimens at temperatures of approximately $60^{\circ} \mathrm{C}$ in an antigen retrieval buffer (most commonly sodium citrate, $\mathrm{pH}$ 6.0) is performed for several minutes, although the time needed for effective retrieval varies widely from antigen to antigen and must be determined experimentally (Daneshtalab, 2010; Shi et al., 2001). In short, antigen retrieval on cultured cells should only be considered as a last resort - if at all possible, an antibody that has been validated for use specifically in ICC (and for the antigen in the species of origin) should be used in order to minimize the chances of requiring any antigen retrieval steps.

\section{Blocking and permeabilization}

Following fixation, but prior to incubation with primary antibodies, cells must be permeabilized in order to allow antibodies to penetrate cellular membranes. Several different detergents are often employed to this end, including Triton X-100, Tween 20 and saponin. They are usually used at concentrations between 0.1 to $0.5 \%$, and are either administered as a separate step prior to blocking, or co-administered with the blocking step. Some protocols specify that a small amount of detergent be kept in the buffers throughout blocking and antibody incubation steps, in order to prevent non-specific interaction of antibodies in different cellular compartments. There are certain exceptions where cells need not be permeabilized; those situations where an antibody is raised against an extracellular region of a membrane protein for instance, or perhaps a component of the extracellular matrix, do not require detergent treatment. In fact, such antibodies can be used to gain insight into the level of surface expression of a particular protein - relative to the total cellular expression - and in studies of trafficking to and from the plasma membrane.

Whether or not it occurs in tandem with solubilization, samples must also be 'blocked,' the process by which all potential antibody binding sites (or 'reactive sites') in the sample are blocked by incubation with a protein with no specific affinity. If this is not carried out, the level of non-specific binding of antibodies to 'off-target' sites will increase dramatically, elevating background signal. For immunostaining of cultured cells, there are two main categories of blocking agent. Normal serum is often used, particularly because it carries immunoglobulins that will bind to reactive sites throughout the sample, reducing the likelihood that the primary antibody will do the same when it is introduced. Optimally, the serum should be sourced from the animal in which the secondary antibody was raised (i.e., when using a goat anti-mouse IgG2a secondary, goat serum should be used). This should further reduce the possibility of excessive binding of primary or secondary antibodies to off-target sites, ensuring a clean, specific staining signal. Bovine serum albumin or nonfat dry milk are also often used. Again, the principle is similar; the primary antibody 'competes' against the proteins in the blocking solution for binding to all available epitopes. Theoretically, the affinity of the antibody for its target is far greater than the affinity of the blocking protein for that same region. Furthermore, the affinity of the antibody for all other, off-target epitopes should, on average, be equal to or lower than that of the blocking protein. The result should be that the antibody binds to only those regions against which it was designed, generating the desired high signal-to-noise ratio. 


\section{Antibodies: their generation, properties and criteria for selection in immunocytochemistry}

\subsection{Polyclonal versus monoclonal antibodies}

Polyclonal antibodies were the original approach to detect an antigen of interest - a process that involved little more than multiple injections into a suitable host animal of the antigen along with an adjuvant to stimulate the immune response. The animal's B-lymphocyte response results in the secretion of multiple distinct antibody molecules (or clones) into the bloodstream, each specific for a single epitope on the antigen. This serum could then be purified and used to stain cells for the antigen of interest. This technique represented a huge leap forward from histological stains (such as the Nissl stain, hematoxylin-eosin, silver nitrate-based methods etc.), but there is a crucial weakness. The availability of the specific antiserum is limited to the lifespan of the animal - after the last batch the animal produced is exhausted, the antibody is virtually lost, with no guarantee that any subsequent immunizations of further animals would produce an antiserum of similar titer and specificity.

In the mid-1970's came the development of monoclonal antibodies. In this system, the first steps are identical to those involved in polyclonal antibody production; an animal (in this instance, usually a mouse, but more recently rabbits too) is immunized with the antigen, perhaps several times, until it is confirmed that there are antigen-specific antibodies in the serum. The spleen is then removed and the splenocytes fused with a myeloma cell line (which is immortal, but doesn't produce antibodies). The resultant hybridomas are selected for by culturing in HAT (hypoxanthine-aminopterin-thymidine) medium. The combination of inhibitors and nucleotide precursors in HAT medium cause the myeloma cells to die because they are unable to synthesize DNA (due to their lack of functional thymidine kinase or hypoxanthine-guanine phosphoribosyltransferase). The unfused B-cells are of course still mortal and will eventually die after a limited number of divisions, leaving a relatively pure population of hybridomas, each one secreting its own specific antibody clone, which can be further subdivided and tested until a single well-performing clone is isolated. The theoretically limitless production of this antibody - as long as the hybridoma is maintained - is key to the phenomenal success of monoclonal antibodies. The antibody produced from this hybridoma or any of its descendants will remain identical in every respect; the value of the reproducible specificity and performance of antibodies generated in this way cannot be overstated (Cambrioso \& Keating, 1992).

That said, polyclonal antibodies still have some advantages in ICC. Since polyclonal antibodies contain many different clones directed against the same antigen, it is possible that they have a greater tolerance for detecting variants of a particular protein of interest, i.e. paralogs, homologs, or proteins with interactions that 'mask' some epitopes. This is something of a double-edged sword, as it can introduce cross-reactivity into the background of a particular stain, but polyclonals are just as likely to be able to detect and bind despite subtle variations in an antigen that a monoclonal, with specificity for just a single epitope, cannot.

\subsection{The importance of validating your antibody}

One of the major difficulties of immunological detection of proteins of interest is nonspecific binding of the antibody, which causes misinterpretation of the obtained results. 
Ensuring the lack of non-specific binding of the antibody is even more important when only a low copy number of the antigen of interest is present, since even a low cross-reactivity with a more abundant protein in these situations could lead to misinterpretation of the results. For example, just a few thousand copies of an ion channel may still have a significant functional contribution to the membrane properties of the cell, but this level of expression may be difficult to detect using ICC and this low level of detection will be overwhelmed when the antibody binds non-specifically to another, more abundantly expressed protein. Testing the antibody specificity is also more important when the antigen to which the antibody was raised shows strong sequence similarity with related proteins. For example, to visualize ion channels at the plasma membrane using ICC, only the small extracellular parts of the ion channel are available for antibody binding. Such extracellular loops are relatively well-conserved between channels belonging to the same subfamily which makes it more difficult to find or generate a unique subunit-specific antibody.

Due to non-specific binding of antibodies, it is important to perform appropriate controls of the antibody's specificity in order to obtain reliable staining. The most reliable way to test an antibody's specificity is to use tissue samples from organisms which lack the specific protein(s) of interest by knocking-out the corresponding genes; all staining that remains in such tissue samples represents non-specific binding of the antibody (Rhodes \& Trimmer, 2006; Saper, 2005). However, there is not a knock-out organism available for every protein of interest, and generating such an organism takes a lot of knowledge, time and money which, if it is solely to test the specificity of an antibody, is impractical. Another way to test the antibody's specificity is by knocking-down the protein of interest in cells that express this protein endogenously using the RNA-interference (RNAi) method. However, with the RNAi approach the majority, but not all copies of the protein of interest are eliminated depending on the turn-over rate - which makes it difficult to discriminate whether detectable staining is originating from residual protein of interest or non-specific binding of the antibody to other proteins. In addition, RNAi also requires specialized knowledge and appropriate controls in order to be performed correctly. The specificity of an antibody can also be tested by pre-incubating the antibody with the antigen or immunizing peptide. In this way it can be determined whether at least a part of the detected staining is originating from the specific binding of the antibody to the protein of interest. However, there is always the possibility that the pre-incubation of the antibody with its antigen or immunizing peptide itself cause a reduction in the staining intensity without being related to the antibody specificity. To determine whether an antibody discriminates between highlyconserved proteins, such as the different members of a voltage-gated potassium (Kv) channel subfamily, different members of this subfamily could be expressed separately in heterologous expression systems and tested for antibody binding. In this case, nontransfected cells must also be tested for antibody binding. This ensures that the antibody is not binding to endogenous cellular proteins and prevents misinterpretation of the results.

\subsection{Appropriate use of antibodies}

Depending on their source and prior purification (if any), an antibody solution may be in one of several different forms. Polyclonal antibodies, if they haven't already been purified may be supplied as whole serum, which needs to be diluted prior to use in the same way as purified antibody, albeit to a much lesser extent. If monoclonal antibodies are not purified, they may be provided as a tissue culture supernatant, literally the tissue culture medium in 
which the relevant hybridoma was grown, and into which the monoclonal antibody was secreted. These preparations haven't been affinity purified, which makes them less timeconsuming and costly to generate, but a larger volume has to be used relative to the blocking solution than if the antibody is purified. The volume of antibody required to achieve good staining in these situations can sometimes be very high relative to the total volume of antibody and diluent, a problem that can sometimes significantly reduce the availability of blocking agent in the solution, potentially compromising binding specificity and increasing background noise. As a precaution, any dilutions of antibodies that will reduce the final concentration of blocking agent by more than $25 \%$ should instead be made with a more concentrated blocking agent to maintain a sufficient final concentration and blocking capacity.

As each antibody generated varies, even if it is targeted against the same epitope, it is difficult to determine with any certainty what concentration of a particular antibody will yield the most satisfactory results. Typically, a good starting range for an antibody on cultured cells is $1-2 \mu \mathrm{g} / \mathrm{ml}$, although this varies significantly, depending on the affinity of the antibody for its epitope. This final concentration may represent a dilution of only 1:5 or 1:10 of whole serum or tissue culture supernatant, but 1:500 or 1:1000 of a purified antibody. The best way to establish good staining with a new antibody is to perform a dilution series across a broad range. This should make it possible to find a dilution that provides optimal signal of the antigen of interest with minimal background. It should also be noted that once diluted to their working concentration, the stability of antibodies is reduced (this principle of maintaining stability of proteins by keeping the total protein concentration of a sample high is the rationale behind supplementing many purified antibody samples with additional protein, usually bovine serum albumin). It is for this reason that solutions of antibodies diluted to their working concentrations should not be kept for more than 24-48 hours.

\subsection{Storage of antibodies}

Antibodies are of course complex protein molecules, and should be treated in the same way as any other protein sample in order to minimize its degradation and preserve its biological activity. In the majority of cases, primary antibodies should be split into small volume aliquots and stored at $-20^{\circ} \mathrm{C}$, whether the solution contains an antifreeze agent such as glycerol or not. This will reduce the number of freeze/thaw cycles the antibody receives, as well as minimizing the risk of contamination. However, there are several important exceptions to this rule: although rare, monoclonal antibodies of the IgG3 isotype are especially vulnerable to forming precipitates upon thawing and should be stored at $4^{\circ} \mathrm{C}$. Furthermore, antibodies conjugated to enzymes should also be stored at $4^{\circ} \mathrm{C}$ to maintain enzyme activity. Sodium azide is often included in antibody solutions as an antimicrobial agent. If desired, it can be added to solutions that don't already contain it to a final concentration of $0.01-0.05 \%$. However, care must be taken that it is not used with secondary antibodies conjugated to horseradish peroxidase (HRP), as sodium azide is a potent inhibitor of HRP activity (Ortiz de Montellano et al., 1988).

\subsection{Secondary antibodies: fluorescent versus enzyme-based methods}

Secondary antibodies are used to indirectly detect an antigen to which the primary antibody has bound. Since the vast majority of commercial antibodies are derived from a small 
number of species, a wide, versatile range of secondary antibodies are available to detect any primary antibody. An additional advantage of using secondary antibodies is that several secondary antibody molecules can bind to each primary antibody molecule, amplifying the signal several-fold versus a directly conjugated antibody (see section 4.6.3). Broadly speaking, there are two classes of covalently-bound tag found on secondary antibodies - fluorophores and enzymes - of which the fluorophore family is more diverse and more widely used in ICC.

Since secondary antibodies are essentially generated by immunizing one species of animal with the antibody from another, they follow the standard 'host anti-target-tag' nomenclature i.e., goat anti-mouse IgG-Alexa Fluor 488. Understanding and paying attention to this nomenclature can also help to avoid a very common pitfall when performing stainings with multiple primary antibodies. Since goats are widely used to generate secondary antibodies, any staining that happens to use a goat polyclonal primary antibody must not employ any secondary antibodies of goat origin, since any anti-goat secondary antibody applied to the sample will also bind secondary antibodies of goat origin present in the sample, since they are also goat IgG molecules. This will generate unexpected labeling patterns and confounding results. This can be avoided by using secondary antibodies from another species (e.g. donkey) in these cases.

In addition to secondaries with class-wide specificity, there are also isotype-specific secondary antibodies, which, depending on the extent of their purification, should only recognize one particular isotype; mouse IgG2a, for example. Affinity purification (passing the secondary through a column containing off-target immunoglobulins) and crossadsorption (effectively filtering the secondary antibody through serum proteins from other species to remove virtually all traces of non-specific binding) are used to generate so-called 'highly cross-adsorbed' secondaries. These allow the end user to simultaneously label several different antigens in the same specimen, primary antibodies permitting. For instance, using isotype-specific secondary antibodies, each labeled with a fluorophore of a different emission wavelength, it is routinely possible to visualize labeling of a rabbit polyclonal, a mouse monoclonal IgG1, IgG2a and IgG2b antibodies, all within the same sample. This of course assumes that the appropriate excitation source and filters are available on the microscope (see section 5).

The number of fluorophore wavelengths available easily exceeds the total number of widely-used antibody classes and subtypes. Commercial suppliers have their own proprietary versions, but the emission wavelengths generally fall into 5 main classes: blue fluorophores (e.g. Alexa Fluor/DyLight 350, 405, AMCA), green (Alexa Fluor/DyLight 488, FITC), yellow-red (DyLight 550, Alexa Fluor 546, 555, Cy3, TRITC), red (DyLight 633, 650, Alexa Fluor 633, 647, Cy5) and near-IR-infrared (Dylight 680, 750, 800, Alexa Fluor 680, 750, Cy5.5).

The principles of isotype specificity also apply to those secondary antibodies conjugated to enzymes (typically horseradish peroxidase (HRP) or alkaline phosphatase (AP) and, more rarely, glucose oxidase), but the detection of antibody binding differs significantly from the fluorescent conjugate approach. In this scenario, a secondary antibody conjugated to HRP or $\mathrm{AP}$ (or perhaps a biotinylated secondary binding an avidin-HRP or avidin-AP conjugate) is incubated with a substrate solution which is converted into a colored precipitate in the immediate vicinity of the enzyme. These additional recruitment and binding stages mean 
that the amplification of the initial signal is greater than with direct conjugates, offering much greater sensitivity. In addition, the precipitates generated from the substrate solutions (or 'chromogens') are observable with a conventional visible light microscope, eliminating the need for fluorescence light sources and optics. In addition, the insoluble deposits left behind from an enzyme's activity should theoretically preclude any interaction of subsequent primary antibodies with that region, meaning that multiple primary antibodies from the same species could be detected, albeit sequentially, in the same specimen (Grube, 2004). There are, however, also some disadvantages to this approach when compared to fluorescence-based strategies. Multiple labeling is possible, since several different substrates are available for each enzyme - red, brown/black and purple colors are possible with the NovaRED, DAB/Ni and VIP substrates for HRP, respectively, as are red, blue and blue/violet with the Red, Blue and BCIP/NBT substrates for AP, but if versatility and routine triple or quadruple labeling are required, fluorescence becomes the more viable option. The additional incubation steps that the enzyme conjugate approach requires take substantially more time than incubation with a fluorophore-conjugated secondary, and there is also the issue (specifically with HRP conjugates) of endogenous peroxidases in cells and tissues which, unless 'quenched' by prior incubation with hydrogen peroxide, may contribute to high levels of background staining.

\subsection{Kits and alternative strategies}

Despite the vast array of antibodies now available, it is highly likely that investigators will eventually encounter a scenario where the staining that needs to be carried out doesn't appear to be compatible with the antibodies that are available. Detailed in this section are three approaches that can be used to circumvent some of these issues.

\subsection{1 'Mouse-on-mouse' kits}

Multiple antibody stainings are a common requirement in studies involving ICC, whether it is used to discover potential interactions between two or more proteins, to label different cell subtypes in a mixed population, or merely to confirm the specificity of one antibody relative to another. All too often, however, the popularity of mouse monoclonal antibodies and the mouse as a model organism means that investigators will be left with no option but to attempt to stain cells of mouse origin with a mouse antibody. This can generate problems when secondary detection methods are used, since a goat anti-mouse IgG secondary antibody may fail to discriminate between the primary antibody IgG molecules and the endogenous IgG molecules expressed by the cells, increasing non-specific staining. There are several commercial kits available designed for these situations that use proprietary blocking solutions or conjugation steps to reduce or eliminate this background staining. However, these so-called 'mouse-on-mouse' kits are of little use when multiple antibodies of the same isotype need to be applied to the same sample, an obstacle that the following two alternative strategies can overcome.

\subsubsection{Zenon labeling}

In many ways, mouse monoclonal antibody technology has become a victim of its own success; frequently there aren't antibodies available in distinct species or isotypes, which precludes specific detection of each signal. Zenon labeling, however, can overcome these 
limitations. In this system, the target specific antibody is incubated with fluorophoreconjugated Fab fragments specific for the Fc region of the antibody to be labeled (e.g. antimouse IgG1 Fab fragments conjugated to Alexa Fluor 488). Following a further incubation with a non-specific IgG (to complex any remaining unbound Fab fragments), the labeled antibody can now be applied to cells in tandem with any other primary antibodies, irrespective of their isotype. The approach is similar in principle to incubating an antibody with a covalently reactive label (and generates fluorescence comparable to that seen with such direct conjugates; see section 4.6.3), however, it affords greater flexibility in terms of switching fluorophore conjugates and no affinity purification of the sample is required postconjugation (van Duijnhoven et al., 2005).

\subsubsection{Direct conjugates}

When multiple antibodies of the same isotype or species need to be applied to cells, another means of solving the issue is to switch to a directly conjugated version of the antibody, which are often commercially available (for example, instead of detecting a mouse IgG1 anti-MAP2 primary with a goat anti-mouse IgG1-Alexa Fluor 488, simply apply a mouse IgG1 anti-MAP2 conjugated to Alexa Fluor 488). There are also commercially available kits that can covalently label even relatively small amounts of antibody with a fluorophore, as little as $10-20 \mu \mathrm{g}$. These approaches can help circumvent issues of isotype availability, but there are some disadvantages. Aside from the additional expense and the limitation of only being able to visualize that antigen in one wavelength, the signal from a direct conjugate will not usually be as intense as with conventional secondary detection, since there hasn't been an additional round of signal amplification (see section 4.5). This means that a higher concentration of antibody may be required to generate signals of sufficient strength, but this may also boost non-specific staining which poses problems, especially if the goal is to detect low abundance proteins. Biotinylated primary antibodies can help overcome some of these amplification issues - subsequent incubation of a sample labeled with a biotinylated primary with an avidin or streptavidin-fluorophore conjugate will boost the signal relative to a fluorophore-conjugated primary, but there are several issues with this system also. Correct blocking of avidin-binding sites using an avidin/biotin blocking kit is almost always required in these circumstances, and the blocking procedure may need to be further altered, since blocking buffers containing nonfat dry milk contain endogenous biotin, a factor that could prevent effective blocking and/or labeling.

\section{Fluorescence microscopy}

Fluorescent molecules are a useful and convenient means of visualizing protein(s)/peptide(s) of interest within a cell and therefore are widely used in ICC. However, fluorescence-based stainings must be interpreted with caution, since the use of fluorescent molecules - especially when using multiple fluorophores together - has a few disadvantages.

\subsection{Bleed-through}

One of the major pitfalls with fluorescence-based stainings is bleed-through. Bleed-through occurs when the emission wavelength of one fluorophore is detected in the emission detection channel of another fluorophore (Fig. 1). This can happen in either direction, i.e. 


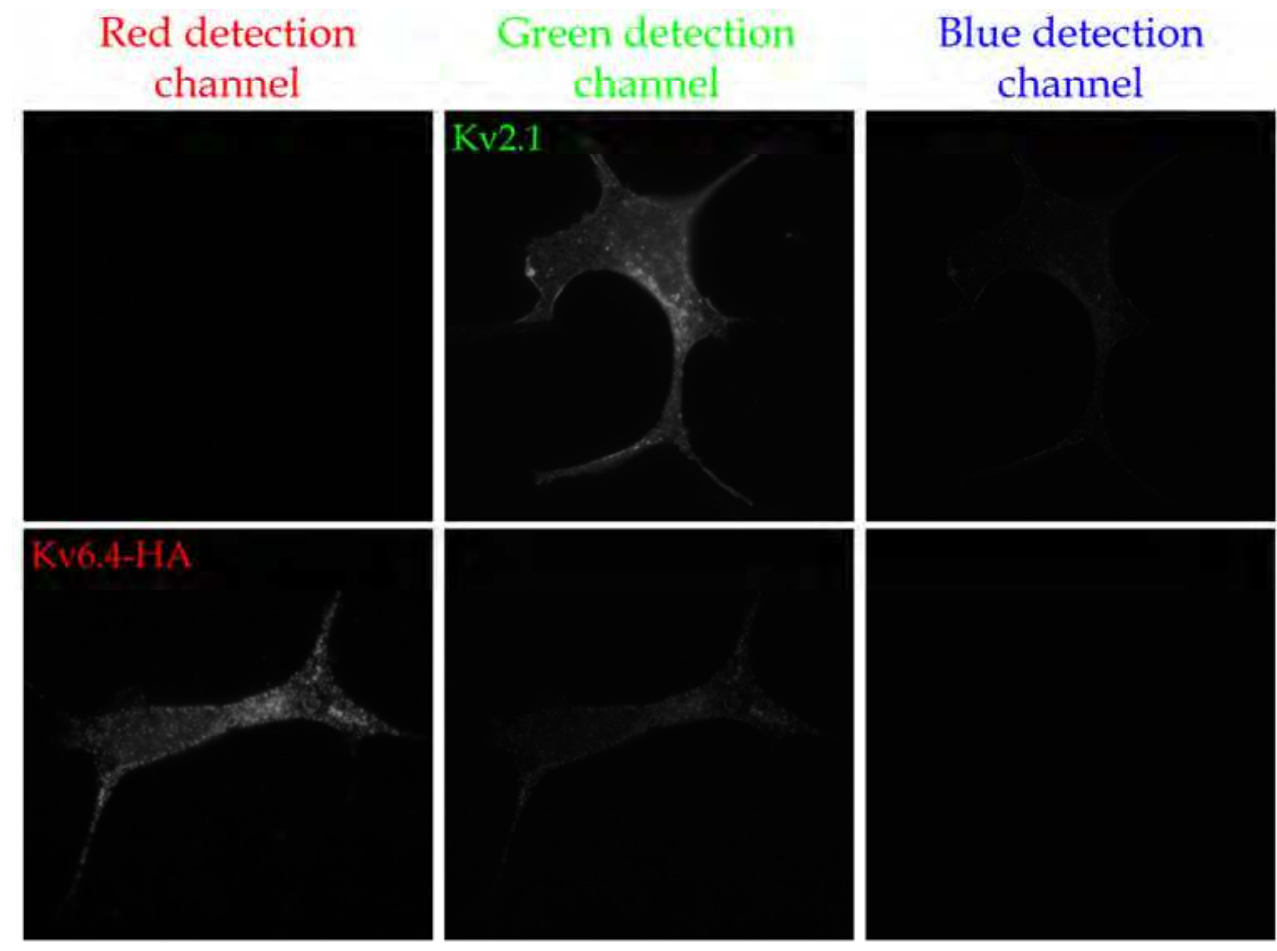

Fig. 1. Bleed-through of the fluorescent signal with immunofluorescence-based detection of voltage-gated $\mathrm{K}^{+}(\mathrm{Kv})$ channel subunits. In the upper row, the expression of Kv2.1 in a HEK293 cell has been fluorescently detected by incubating with a Kv2.1-specific antibody $(1 \mu \mathrm{g} / \mathrm{ml}$; K89 from NeuroMab, UC Davis, CA, USA) followed by a green Alexa Fluor 488 labeled goat anti-mouse IgG1 secondary antibody (1/1600 dilution, Invitrogen, San Diego, CA, USA). The lower row represents a HEK293 cell expressing HA-labeled Kv6.4, which was detected by incubating with a HA-specific antibody $(4 \mu \mathrm{g} / \mathrm{ml} ; 12 \mathrm{CA} 5$ from Roche Diagnostics, Basel, Switzerland) followed by a red Alexa Fluor 555 labeled goat anti-mouse IgG2b secondary antibody (1/1600 dilution, Invitrogen). In each row, the left, middle and right image represents the red, green and blue detection channel, respectively. Note the slight bleed-through of the green fluorescent Kv2.1 signal in the blue detection channel (upper row) and the more pronounced bleed-through of the red fluorescent Kv6.4-HA signal in the green detection channel (lower row).

bleed-through from a shorter wavelength into a longer wavelength's detection channel and vice versa. Due to bleed-through, results can be interpreted incorrectly; it can be mistakenly believed that the protein of interest was detected in its wavelength detection channel, when in reality only the emission of a fluorophore used to observe another protein was detected. Bleed-through can be minimized by using fluorophores where the emission wavelengths are widely separated from each other; when one protein of interest is detected at a shorter wavelength (350 $\mathrm{nm}$ for example) and the other protein of interest is investigated in a longer wavelength detection channel (650 $\mathrm{nm}$ for example), bleed-through of emission of one 
wavelength in the other detection channel will not occur. However, detecting proteins in those shorter and longer wavelengths is only possible when the detected protein is present in abundance and the antibodies used are providing a strong signal, since weaker fluorescent signals are more difficult to observe in longer wavelengths such as $650 \mathrm{~nm}$. In addition, the far red and infrared detection channels (i.e. $650 \mathrm{~nm}$ and above) are not especially common detection channels on most conventional fluorescent microscopes. Although bleed-through can happen in either direction, bleed-through usually occurs from a lower emission wavelength detection channel into a higher emission wavelength detection channel. Therefore, it may be better to start imaging with higher wavelengths and continue imaging toward lower wavelengths when multiple fluorphores are used to minimize bleedthrough. Bleed-through can also be minimized by minimizing the exposure time of the fluorophore to the lowest necessary level; minimizing the exposure time would also decrease the excitation of the fluorophore causing the bleed-through. If possible, the specificity of the emission spectrum reaching the camera/eyepieces can be increased by employing bandpass filters specific for the fluorophore in question rather than the less specific and less costly short or long-pass filters.

\subsection{Background and non-specific signals}

Another major pitfall of fluorescence-based staining is background fluorescence. This could be caused by autofluorescence of the sample, non-specific binding of the antibody in the case of immunostainings and/or non-specific excitation of another fluorophore by the selected excitation wavelength when multiple fluorophores are used. Such background fluorescence is a particular problem when the fluorescent signal of interest is relatively weak. With stronger fluorescent signals of interest the microscope settings can easily be changed (i.e. lower laser strength and lower gain) to minimize background fluorescence. However, with a weaker fluorescent signal, reducing the microscope settings will mask the signal of interest. In this case trying to obtain a stronger fluorescent signal of interest is the only way to discriminate between background fluorescence and the fluorescent signal of interest. An increased fluorescent signal of interest can be achieved by using a primary antibody that exhibits less non-specific binding and/or provides a stronger signal by having a stronger binding affinity to the protein of interest and/or by using another detection channel (i.e. fluorescent signals can be easier to detect in shorter wavelengths). Since secondary antibodies can also exhibit non-specific binding, secondary antibodies can also contribute to background fluorescence. To determine whether secondary antibodies are also causing background fluorescence, the sample can be incubated with the secondary antibody alone; any remaining fluorescence is by definition background fluorescence. To avoid such background fluorescence, it may help to optimize the dilution of the secondary antibody, or switch to an alternative secondary antibody.

\subsection{Discerning the signals}

Due to limitations in microscope resolution, it is difficult to discern the presence of a few proteins at the plasma membrane (PM) when the majority resides in the endoplasmic reticulum (ER). This could be solved by making z-stack images on a confocal microscope. These are generated by sequentially focusing on a thin horizontal section of the cell, and 
generating a final composite of the stack in each image. However, the cost of a confocal microscope is almost five times a conventional microscope and is therefore not always an option. Another way to determine the presence of a few proteins at the PM when the majority is localized in the ER is by performing surface staining prior to cell permeabilization. However, surface staining can also be a challenge; just a few thousand copies of a (trans)membrane protein such as ion channels may still have significant functional contributions to the cell membrane properties, but this level of expression may be difficult to detect using immuno-based surface staining.

\subsection{Focusing level}

To prevent misinterpretation of the results using fluorescence microscopy it is also important to know the level within the cell at which the microscope is focused. For example, the voltage-gated $\mathrm{K}^{+}(\mathrm{Kv})$ channel $\mathrm{Kv} 2.1$ demonstrates a clustered membrane staining pattern both natively in neurons and in heterologous expression systems (Mohapatra et al., 2008; Scannevin et al., 1996; Vacher et al., 2008). However, this is only visible when focused on the cell membrane (Fig. 2, left). When the focus lays more on intracellular cell compartments/organelles, these Kv2.1 clusters are no longer detectable and the Kv2.1 membrane localization is only visible as a colored 'ring' around the edge of the cell (Fig. 2, right).
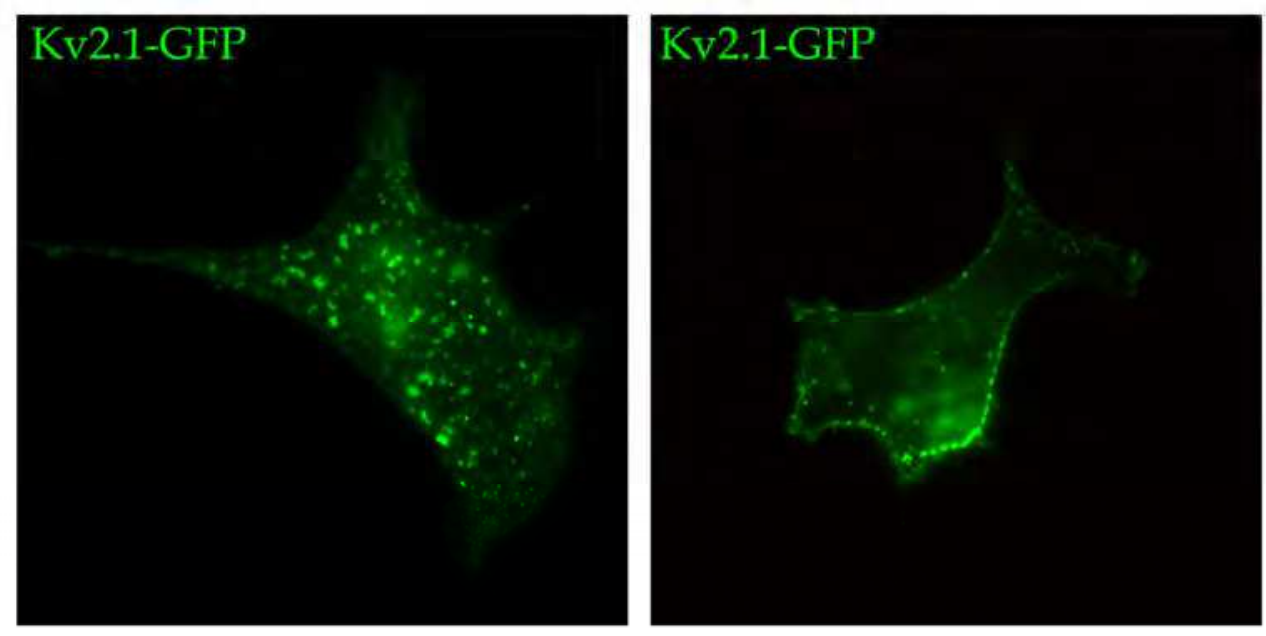

Fig. 2. Visualization of the plasma membrane (PM) localization of the voltage-gated $\mathrm{K}^{+}(\mathrm{Kv})$ subunit Kv2.1 depends on the level in the cell at which the microscope is focused. Both left and right images show a representative HEK293 cell expressing GFP-labeled Kv2.1. When the focus in the cell is on the PM, the clustered PM localization of Kv2.1 is readily detectable (left image) while the Kv2.1 PM localization is only noticeable as a colored 'ring' around the edge of the cell when the focal plane lies deeper in the cell (right image). 


\subsection{Bleaching and weakening of fluorescent signals}

A last point that has to be taken into account when using fluorescent molecules to detect proteins of interest is bleaching. Fluorophores are highly light sensitive and exposure of those fluorescent molecules to light cause bleaching of the fluorophore. Because of this, weak signals could disappear before detection, resulting in misinterpretation of the results. To avoid this, exposure of the fluorophores to light has to be minimized which includes storing the fluorophores in a dark place, covering the samples during incubation with fluorophore conjugates and minimizing the exposure of the fluorophores to light when images are taken.

\section{Alternative approaches}

Because the use of antibodies to investigate the (co-)localization of proteins experimentally is usually not that easy as it is in theory, it is sometimes more convenient to use geneticallyencoded fluorescent proteins to define the (sub-)cellular expression of the protein(s)/peptide(s) of interest and to define specific cellular compartments/organelles.

\subsection{Genetically-encoded labels}

To examine the (co-)localization of one or more proteins of interest in cells, those proteins can be labeled with a genetically-encoded fluorescent label, such as green fluorescent protein (GFP) or its yellow (YFP), cyan (CFP), blue (BFP) or red (RFP) variants, in which a mutation in the GFP chromophore is introduced to change the color. To obtain such genetically-encoded fluorescent labeled proteins, the cDNA of the fluorescent label and that of the protein of interest have to be cloned in frame with each other.

The use of genetically-encoded protein labels has a few major advantages compared to the use of immunofluorescent detection of the protein of interest. Using genetically-encoded labeled proteins allows experiments to be performed in live cells, which eliminates possible artifacts that could occur as a result of cell fixation. In addition, this opens the opportunity to perform live cell imaging - in which changes in a protein's localization can be tracked in real-time within the same cell. The use of genetically-encoded labeled proteins also permits less protein to be expressed in order to be able to visualize the protein of interest in cells, since the fluorescent signal of genetically-encoded labels is stronger than that of immunofluorescence-based stainings. For example, at least $1 \mu \mathrm{g}$ of the plasmid containing the $\mathrm{Kv}$ channel Kv2.1 cDNA has to be transfected to observe good clustered plasma membrane staining when antibodies are used while only $100 \mathrm{ng}$ GFP-labeled Kv2.1 has to be transfected to obtain a similar Kv2.1 plasma membrane staining. Because less protein has to be expressed, possible artifacts caused by an overload of the cell transcription/translational machinery are minimized. Using genetically-encoded labeled proteins also eliminate nonspecific/background staining caused by non-specific binding of the used antibodies in immunofluorescence-based stainings.

As with any experimental technique, the use of genetically-encoded labeled proteins also has some disadvantages which have to be taken into account. GFP and its variants are fairly large proteins $(\sim 30 \mathrm{kDa})$ which are added to the protein of interest. This could result in changes in the native properties of the protein or in native protein-protein interactions. Therefore, one always has to verify that the properties of the fluorescentlylabeled fusion protein have not significantly been changed compared to the non-labeled 
protein. In the case of ion channels, this can be easily determined based on the electrophysiological properties of the channels using the patch clamp technique. Even if the native properties of a genetically-encoded fluorescent-labeled protein have not been changed, such labeled proteins cannot readily be used to investigate the localization of native proteins in native cells (such as neurons), since those genetically-encoded labeled proteins always have to be transfected into cells or introduced into the animal (i.e. GFP knock-in mice).

\subsection{Genetically-encoded marker proteins to identify cellular compartments}

In addition to the fluorescent labels used to localize a protein of interest in live cells, different cellular compartments can also be identified by transfecting genetically-encoded fluorescent proteins. Those proteins are so modified that they are targeted to a certain cellular compartment using established signal sequences.

DsRED-ER is a genetically-encoded fluorescent protein that stains the endoplasmic reticulum (ER) red when expressed in cells. This ER marker was produced by cloning the first 17 amino acids of calreticulin (the ER signal sequence) in frame with the DsRED sequence and adding the ER retention signal KDEL behind the DsRED sequence (Ottschytsch et al., 2002). Co-transfecting this ER marker with a protein of interest into cells can reveal whether this protein of interest is located in the ER or not, as demonstrated in figure 3. Co-transfection of DsRED-ER with the GFP-labeled silent $\mathrm{Kv}$ subunit Kv6.4 demonstrated a maximal overlap of the green GFP staining pattern with the red DsRED-ER staining pattern, indicating that this Kv6.4-GFP subunit is retained in the ER. In contrast, the green staining pattern of Kv2.1-GFP shows minimal overlap with the DsRED-ER staining, indicating that this Kv2.1 channel is not localized in the ER.

The genetically-encoded fluorescent protein mtGFP labels the mitochondria green when transfected into cells. This mitochondrial marker was obtained by consecutively subcloning the sequence encoding the N-terminal 31 amino acids of the precursor of subunit VIII of cytochrome $c$ oxidase (COX8) which is an endogenous mitochondrial transmembrane protein and therefore acts as the mitochondrial targeting sequence, the sequence encoding the hemagglutinin HA1 epitope and the sequence encoding GFP in frame with each other (Rizutto et al., 1995). mtGFP can be used to visualize the mitochondria and to investigate whether a protein of interest is localized to the mitochondria or not. Figure 4 demonstrates this; no overlap could be observed between the red clustered membrane staining pattern of $\mathrm{Kv} 2.1-\mathrm{RFP}$ with the green staining pattern of mtGFP, indicating that this $\mathrm{Kv}$ channel is not located in the mitochondria. Mitochondria can also be visualized with the use of mtPericam that labels the mitochondria green after transfecting into cells. In addition, mtPericam, due to its $\mathrm{Ca}^{2+}$ sensitivity, can be used to investigate changes in the intracellular mitochondrial $\mathrm{Ca}^{2+}$ concentration; its fluorescence intensity changes with changes in intracellular mitochondrial $\mathrm{Ca}^{2+}$ concentrations. mtPericam is a chimeric protein consisting of (consecutively): the N-terminal 12 amino acid presequence of subunit IV of cytochrome $\mathrm{c}$ oxidase (COX4), M13 which is a 26 amino acid-long peptide derived from the calmodulin (CaM)-binding region of the skeletal muscle light-chain kinase, circularly permuted GFP (cpGFP) in which the N-and C-terminus of GFP are linked to each other, and CaM (Nagai et al., 2001). 

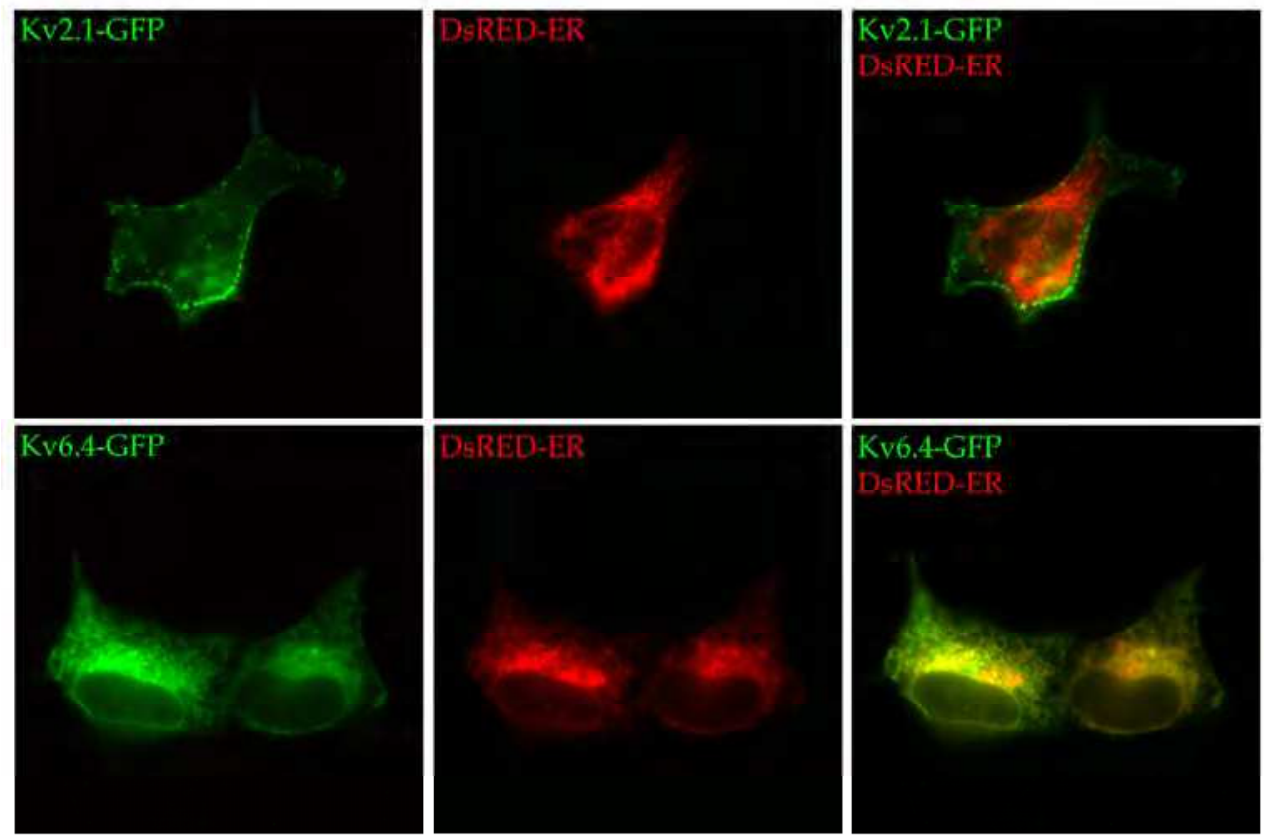

Fig. 3. Localization of GFP-labeled voltage-gated $\mathrm{K}^{+}(\mathrm{Kv})$ channels in the endoplasmatic reticulum (ER) using the ER marker DsRED-ER. The upper and lower rows represent typical images of GFP-labeled Kv2.1 and Kv6.4 subunits in HEK293 cells. The left, middle and right image represent the green GFP fluorescence, the red DsRED-ER fluorescence and the overlay of both fluorescent signals, respectively. The green fluorescent staining pattern of Kv2.1-GFP demonstrates minimal overlap with the red DsRED-ER staining pattern, indicating that Kv2.1-GFP is not located in the ER. Kv6.4-GFP, on the other hand, is localized almost entirely in the ER which is noticeable in the maximal overlap of the green Kv6.4-GFP staining pattern with the red DsRED-ER staining pattern.

Lck-mCherry is a genetically-encoded fluorescent protein that stains the PM red after transfecting into cells. This PM marker is obtained by attaching the myristoylation/palmitylation motif from the Lck tyrosine kinase to the N-terminus of mCherry (Naumann et al., 2010). After co-transfecting Lck-mCherry with a protein of interest, it can be determined whether this protein of interest is localized at the PM or not. In figure 5, the PM localization of transiently transfected Kv2.1-GFP in HEK293 cells is confirmed by the maximal overlap of its green PM staining pattern with the red staining pattern of the PM marker Lck-mCherry. In addition, Kv6.4-GFP is not located at the PM since no overlap between the green staining pattern of Kv6.4-GFP and the red staining pattern of Lck-mCherry could be detected. 

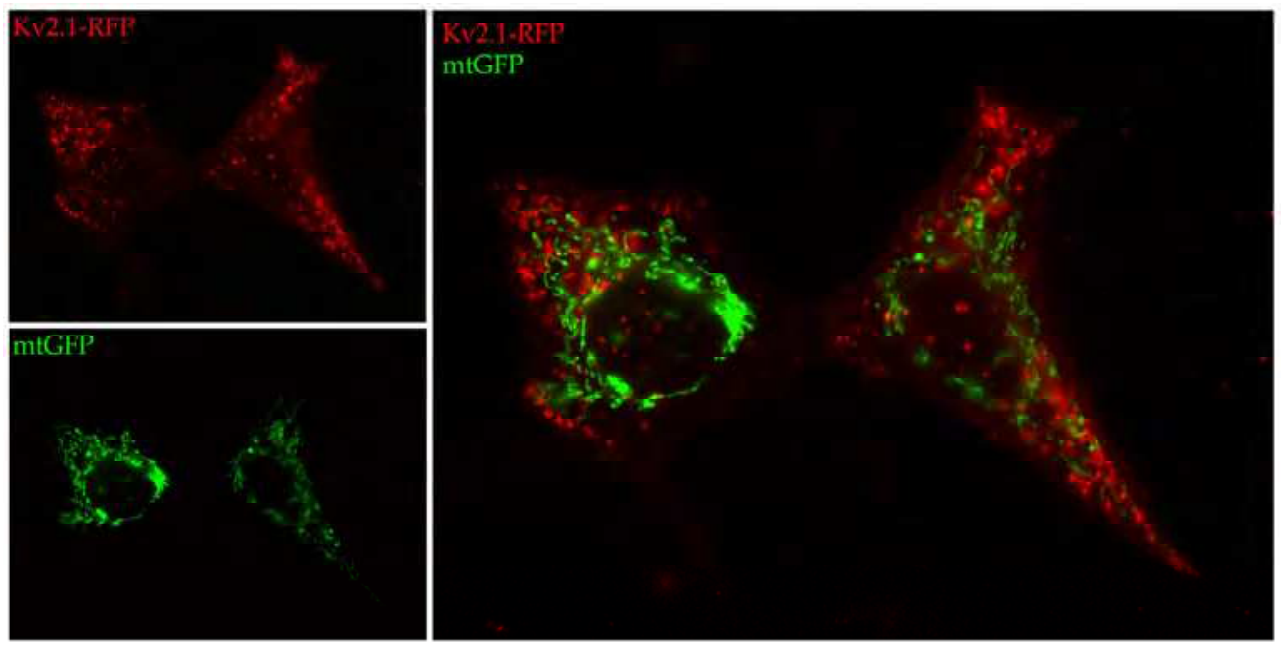

Fig. 4. Localization of the RFP-labeled voltage-gated $\mathrm{K}^{+}(\mathrm{Kv})$ channel $\mathrm{Kv} 2.1$ in comparison to the mitochondria by using the mitochondrial marker mtGFP. Shown are representative HEK293 cells expressing Kv2.1-RFP. The left upper and left lower images represent the red RFP fluorescence and the green mtGFP fluorescence, respectively. The image on the right represents the overlay of both fluorescent signals. Note that Kv2.1-RFP (consistent with its efficient trafficking to the plasma membrane) is not localized in the mitochondria since no overlap between the red Kv2.1-RFP staining pattern and the green mtGFP staining pattern is observed.

The above-mentioned genetically-encoded marker proteins for cellular compartments can be used in both heterologous expression systems such as HEK293 cells as well as native cells such as neurons by transfecting those marker proteins in the cells of interest. However, neurons are not as amenable to transfection as heterologous cells, and transfection could also change the native properties of the neuron. For this reason, using antibodies raised against endogenous marker proteins of a certain cellular compartment is a useful alternative that can be used to differentiate cellular compartments in neurons. In this case antibodies raised against the cis-Golgi matrix protein GM130, early endosome-associated protein EEA1, Calnexin and E-Cadherin could be used to indicate Golgi (Nakamura et al., 1995), endosomes (Mu et al., 1995), ER (Wada et al., 1991) and PM (Volk \& Geiger, 1984), respectively.

In addition to the genetically-encoded cellular compartment/organelles markers, there also exist phenotypic markers to differentiate cell types. For example, using antibodies raised against the endogenously expressed microtubule-associated protein 2B (MAP2B) and glial fibrillary acidic protein (GFAP) allow investigators to determine whether a protein of interest is expressed in neurons (Izant \& McIntosh, 1980) or in glial cells (Raff et al., 1979), respectively, since it is not always that easy to discriminate neuronal from glial cells based 
on their morphological properties alone. This is demonstrated in figure 6; Kv2.1 (represented by green fluorescence) is expressed in rat hippocampal neurons (marked by the blue staining pattern of MAP2B) and not in glial cells (marked by the red staining pattern of GFAP).
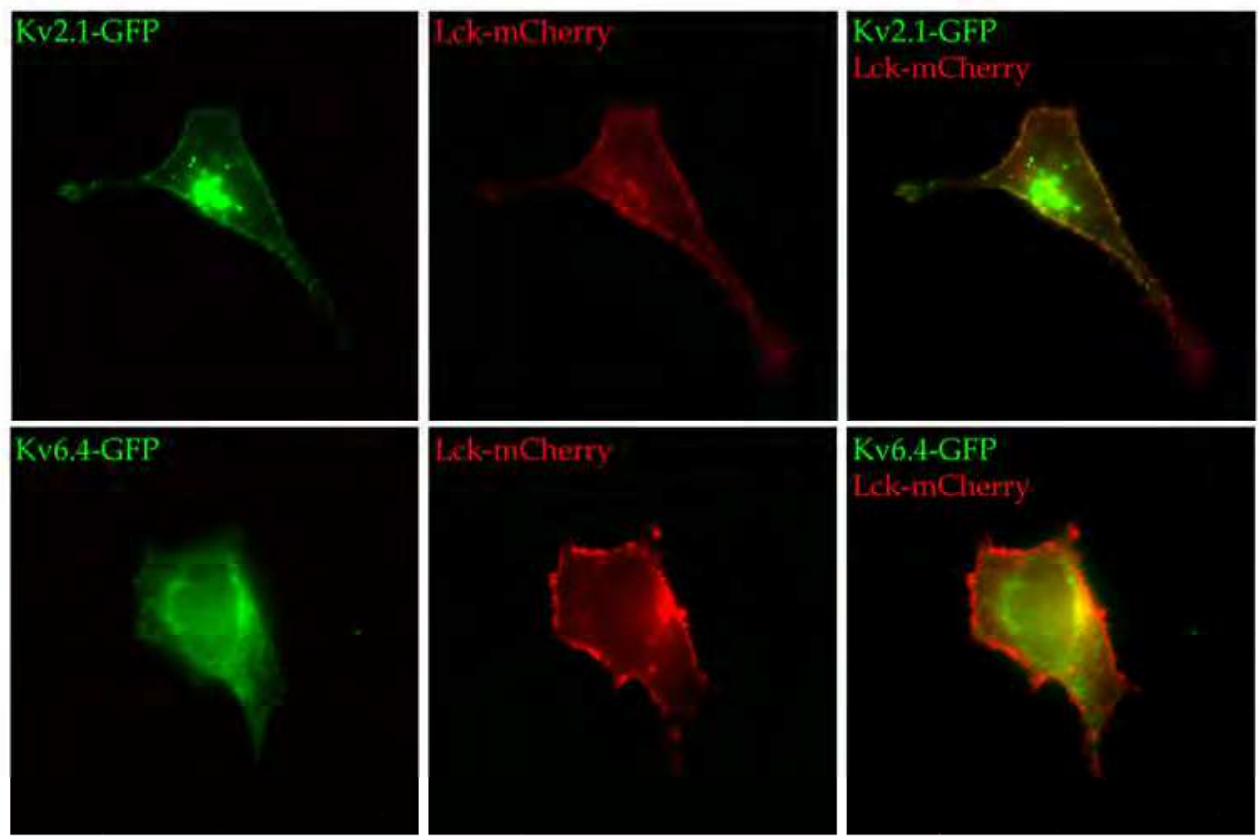

Fig. 5. Localization of GFP-labeled voltage-gated $\mathrm{K}^{+}(\mathrm{Kv})$ channels at the plasma membrane (PM) in HEK293 cells using the PM marker Lck-mCherry. The upper and lower rows represent typical images of GFP-labeled Kv2.1 and Kv6.4 subunits in HEK293 cells. The left, middle and right images on both rows represent the green GFP fluorescence, the red LckmCherry fluorescence and the overlay of both fluorescent signals, respectively. The green fluorescent signal of Kv2.1-GFP demonstrates substantial overlap with the red Lck-mCherry signal, indicating that Kv2.1-GFP is located at the PM. Kv6.4-GFP is not localized at the PM, which is exemplified by the minimal overlap of the green Kv6.4-GFP signal with the red Lck-mCherry signal.

\subsection{Fluorescence Resonance Energy Transfer (FRET)}

ICC can tell us about co-localization of proteins/peptides of interest due to the overlap of different fluorescent staining patterns, but it cannot tell us if both proteins are merely adjacent to one another, or if their physical proximity is the result of a functional interaction. Fluorescence resonance energy transfer (FRET) can be used to determine both colocalization and actual interaction between the proteins of interest (Kenworthy, 2001). 


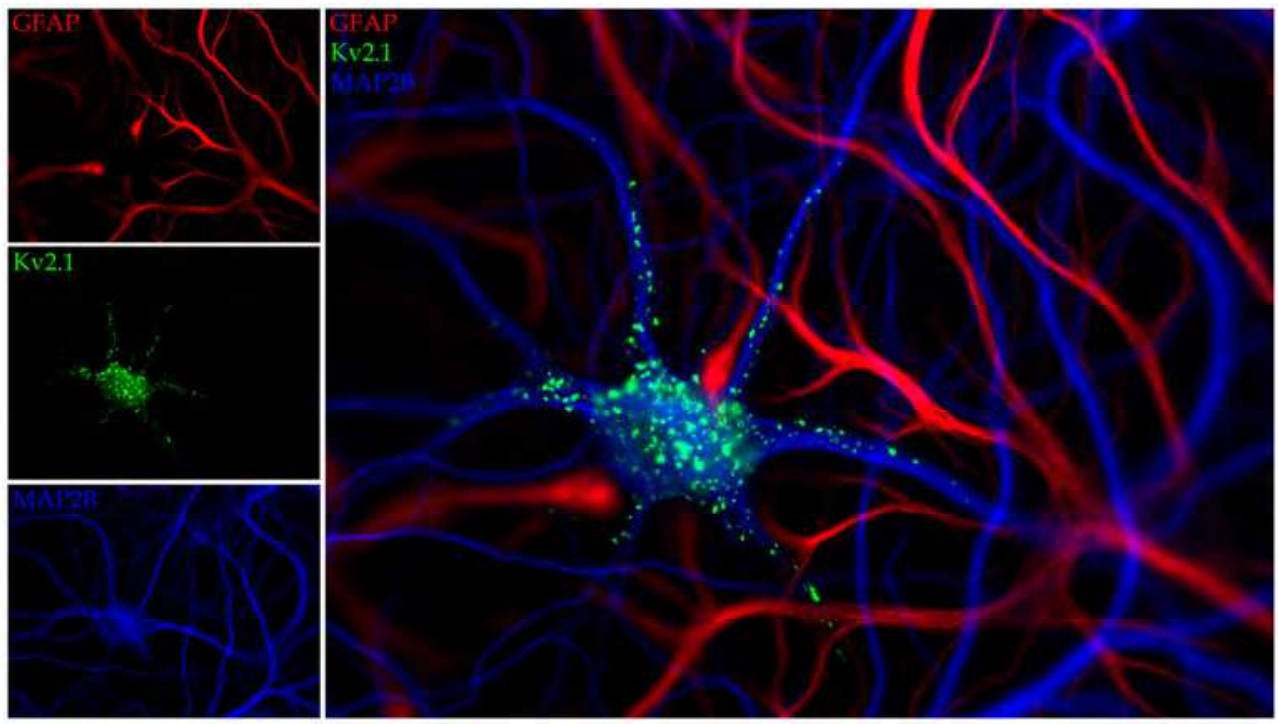

Fig. 6. Localization of the voltage-gated $\mathrm{K}^{+}(\mathrm{Kv})$ channel Kv2.1 in cultured rat hippocampal neurons using neuronal and glial cell marker antibodies. In the left column, the upper, middle and lower images represent the red GFAP fluorescence, the green Kv2.1 fluorescence and the blue MAP2B fluorescence, respectively. The image on the right represents the overlay of the three fluorescent signals. Note that Kv2.1 expression is confined to the blue hippocampal neuron and absent from the red glial cell processes.

FRET, also known as Förster resonance energy transfer, is the radiation-free transmission of energy from a donor molecule, which is the chromophore that initially absorbs the energy, to an acceptor molecule, the chromophore to which the energy is subsequently transferred (Förster, 1948). FRET can only occur between two chromophores when the following criteria have been fulfilled: (i) the donor and acceptor molecule must be situated in a range within $10 \AA(1 \mathrm{~nm})$ and $100 \AA(10 \mathrm{~nm})$ of each other since closer proximity $(<10 \AA)$ will allow several other ways of energy transfer while more distance (> $100 \AA$ ) will prevent the radiation-free energy transmission, (ii) the donor emission spectrum has to have a certain spectral overlap with the acceptor absorption spectrum and (iii) the donor emission dipole moment has to be almost parallel with the acceptor absorption dipole moment.

When FRET occurs, light emitted by the acceptor will be observed after excitation of the sample with the donor excitation wavelength. However, bleed-through of donor emission light in the acceptor emission detection channel, as well as direct excitation of the acceptor chromophore by the donor excitation wavelength through to overlap in the donor and acceptor excitation spectra could result in detecting acceptor emission light even when no 
FRET actually takes place. Therefore, it is better to determine the occurrence of FRET based on changes in the donor fluorescence. FRET results in both a decrease of the donor fluorescence lifetime and the donor fluorescence intensity, the latter of which is more convenient to determine.

Based on the donor fluorescence intensity, the efficiency with which FRET occurs can be determined with following equation:

$$
\text { FRET }=\left(1-\frac{f_{D A}-f_{\text {background }}}{f_{D}-f_{\text {background }}}\right) x \frac{1}{\text { paired }_{D A}}
$$

In which $f_{D A}$ represents the fluorescence intensity of the donor in the presence of the acceptor, $f_{D}$ the fluorescence intensity of the donor in the absence of the acceptor, $f_{\text {background }}$ the background fluorescence intensity, and paired $\mathrm{DA}_{\mathrm{DA}}$ the fraction of paired donor-acceptor chromophores. The donor fluorescence intensity in the presence of the acceptor $\left(f_{D A}\right)$ is determined by recording the donor emission light after exciting the sample with the donor excitation wavelength. By eliminating the acceptor chromophore which is obtained by bleaching the acceptor molecule with full power acceptor excitation wavelength laser light, the donor fluorescence intensity in the absence of the acceptor $\left(f_{D}\right)$ is obtained. If FRET occurs, eliminating the acceptor chromophore by bleaching will result in an increase of the donor fluorescence intensity since the donor will no longer be able to transfer its energy to the acceptor molecule (Fig. 7). The background fluorescence ( $\left.f_{\text {background }}\right)$ is determined by recording the donor emission light after bleaching of the donor chromophore with full power donor excitation wavelength laser light. When the fraction paired donor-acceptor chromophores (paired $\mathrm{DA}_{\mathrm{DA}}$ ) cannot be determined precisely (which is mostly the case when both chromophores are introduced in different proteins of which the interaction is tested) the acceptor chromophore has to be "over expressed" in comparison to the donor chromophore to ensure that this fraction is 1 and that the FRET efficiency can be determined adequately.

To prevent misinterpretation of the obtained results, two ratios have to be taken into account when determining FRET efficiencies; both the donor:acceptor intensity ratio and the background:signal intensity ratio have to be high enough. If the donor:acceptor intensity ratio is too small $(<1)$, FRET efficiencies will be underestimated, while a high background:signal intensity ratio will overestimate the effective FRET efficiency.

Not all possible chromophore pairs can be used to perform FRET experiments. A good FRET donor-acceptor pair must fulfill the following criteria: (i) the acceptor and donor excitation spectra have to be separated enough so that the acceptor chromophore has been excited minimally after excitation of the donor molecule, (ii) the acceptor and donor emission spectra have to be separated sufficiently such that the emission spectra of the donor is detected minimally at the acceptor emission detection wavelength and (iii) the donor emission and acceptor excitation spectra have to demonstrate a maximal overlap with each other so that the acceptor chromophore is excited by the donor's emission wavelength after being excited with its own excitation wavelength. Due to these criteria, the optimal excitation and emission wavelength of both donor and acceptor molecule is not always at the maximum of their excitation and emission spectra. 
A

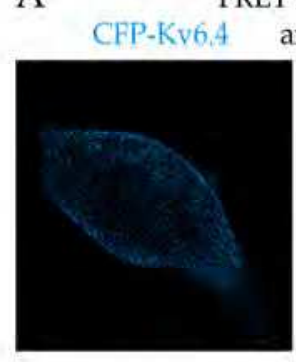

FRET between

and

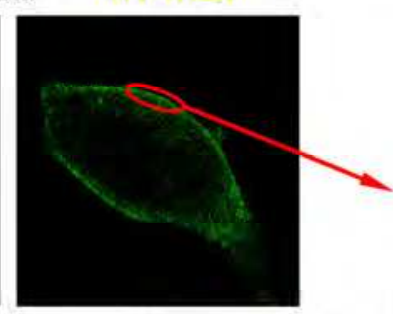

YFP bleach
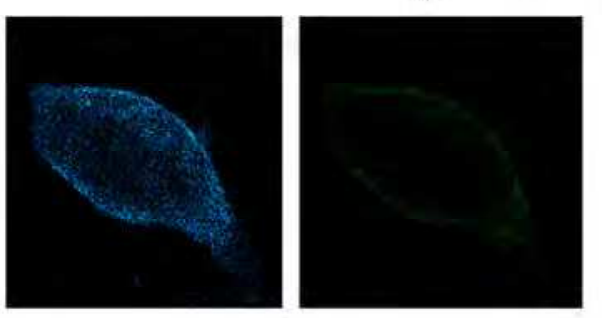

B

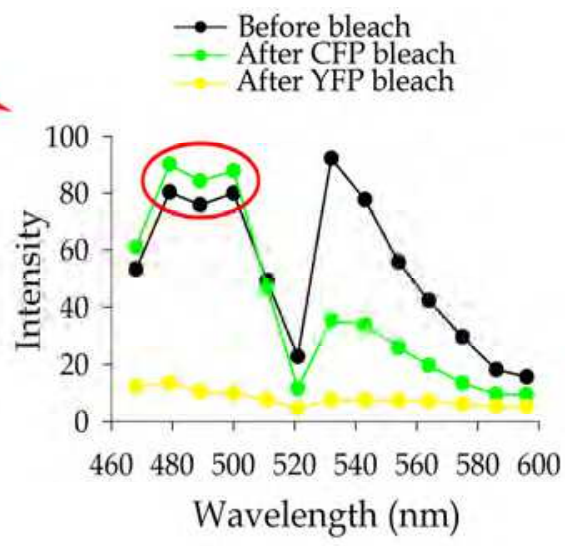

Fig. 7. Interaction between voltage-gated $\mathrm{K}^{+}(\mathrm{Kv})$ subunits determined by FRET using CFP and YFP-labeled Kv channel constructs. (A) Representative cell expressing both Nterminally labeled CFP-Kv6.4 and YFP-Kv2.1 subunits. The panels on the left and right show the CFP and YFP emission light after excitation with the CFP excitation wavelength (in this case $458 \mathrm{~nm}$ ), respectively, while the top and bottom panels represent CFP and YFP emissions before and after bleaching of YFP in the whole cell, respectively. If FRET occurs, the CFP emission is underestimated since CFP transfers its emission light onto YFP which is relieved by eliminating YFP by bleaching with full power YFP excitation wavelength laser light (514 $\mathrm{nm}$ in this case); note the increased CFP intensity and the decreased YFP emission after YFP bleach. (B) Recorded emission spectra of the indicated region in panel A (red oval) before (black line) and after (green line) YFP bleaching. Note the increase in intensity in the CFP detection wavelengths (indicated by the red circle) and the significant decrease in the YFP detection wavelength intensity after YFP is bleached in the whole cell. Background signal (yellow line) was determined after fully bleaching CFP. 
The donor-acceptor pair CFP-YFP fulfills these criteria reasonably and is therefore often used as a FRET donor-acceptor pair. Another good FRET donor-acceptor pair is the donoracceptor pair BFP-GFP (Pollok \& Heim, 1999). In addition to the genetically-encoded chromophores, organic cyanine dyes such as $\mathrm{Cy} 3$ and $\mathrm{Cy} 5$ which act as donor and acceptor chromophore, respectively, are also often used to perform FRET experiments. Those dyes have some advantages compared to the genetically-encoded chromophores (i.e. less spectral overlap between the donor emission and acceptor excitation spectrum is required and larger distances between both chromophores are possible) but these organic cyanine dyes have to be chemically linked to the proteins of interest which is a great disadvantage.

The position in which the acceptor/donor chromophore is introduced into the protein of interest is very important when performing FRET experiments. In addition to the fact that these chromophores could change the properties of the native protein significantly, it is also possible that those chromophores are introduced into the proteins at positions where the distance between both chromophores is too large to observe FRET. For example, when the interaction between voltage-gated $\mathrm{K}^{+}$subunits is investigated by FRET experiments, the subunits have to be labeled N-terminally and not C-terminally since no FRET could be observed when those subunits are labeled C-terminally although those subunits physically interact with each other in a functional tetrameric $\mathrm{Kv}$ channel (Bocksteins et al., 2009; Kobrinsky et al., 2006).

In addition to using FRET to investigate whether two proteins of interest only co-localize or actually interact with each other, FRET can also be used to ascertain whether the lack of functional membrane proteins at the PM is due to a trafficking or tetramerization deficiency (Bocksteins et al., 2009). For this purpose, the FRET efficiency in both a region that represents the PM and a region that represents the ER has to be determined. When a trafficking deficiency causes the lack of functional membrane proteins at the PM, FRET could still be observed in the ER while a tetramerization deficiency would also eliminate FRET in the ER. With this approach, it has been demonstrated that the reduced PM expression of mutant Kv2.1 channels was due to a tetramerization deficiency, since the observed reduced current amplitude of those mutant channels was accompanied by a significant reduction of FRET in the ER (Bocksteins et al., 2009).

\section{Conclusion}

ICC is a powerful, versatile tool for furthering our understanding of the expression, localization and interactions of proteins at the cellular level. This power has only been augmented by more recent developments in molecular biology, where insights into the behavior of proteins in live cells, or interactions on the atomic scale can now be investigated. Unfortunately, there are many ways in which the results of ICC can be sub-optimal or completely negative if attention isn't paid to certain key concepts, and an understanding of the principles involved isn't developed. Taking voltage-gated ion channels and neurons as our examples, we have explained the core principles behind the most widely-used techniques in ICC: how to correctly fix cells so that the structure of even complex transmembrane proteins will be preserved faithfully; the processes of blocking and permeabilization and the ways in which they can be modified to ensure the best possible results; the importance of the difference between monoclonal and polyclonal antibodies and 
how the signals from antibodies of interest should be validated; as well as the dilution and storage conditions that will minimize the loss of antibody activity. Secondary antibody options were detailed, explaining the strengths and weaknesses associated with the common approaches to detecting primary antibody signal. Alternative strategies, which can enable staining that wasn't previously possible, were outlined, as were the limitations and errors that are frequently encountered in fluorescence microscopy. Finally, we discussed approaches that can complement antibody-based studies, namely the transfection of fluorescent-labeled constructs targeted to specific sub-cellular compartments, and the use of FRET to discover if two proteins that appear in close proximity are physically interacting or not. The combined powers of these techniques still have a great deal to teach us across the life sciences as a whole, and will continue to be an integral part of studies therein for the foreseeable future.

\section{Acknowledgments}

We thank Dr. Yuriy Usachev and Dr. Stefan Strack, Department of Pharmacology, The University of Iowa Carver College of Medicine for kindly providing us with the mammalian expression plasmids containing mtGFP and Lck-mCherry cDNA, respectively.

\section{References}

Bocksteins, E., Labro, A.J., Mayeur, E., Bruyns, T., Timmermans, J.P., Adriaensen, D. \& Snyders, D.J. (2009). Conserved negative charges in the N-terminal tetramerization domain mediate efficient assembly of Kv2.1 and Kv2.1/Kv6.4 channels. The Journal of Biological Chemistry, Vol. 284, No. 46 (November 2009), pp.31625-31634, ISSN 0021-9258.

Burry, R.W., (2010). Immunocytochemsitry: A Practical Guide for Biomedical Research. Springer, ISBN 978-1441913036, New York, New York.

Cambrioso, A. \& Keating, P. (1992). Between Fact and Technique: The Beginnings of Hybridoma Technology. Journal of the History of Biology, Vol. 25, No. 2 (Summer 1992), pp. 175-230, ISSN 0022-5010.

Daneshtalab, N., Doré, J.J. \& Smeda, J.S. (2010). Troubleshooting tissue specificity and antibody selection: Procedures in immunohistochemical studies. Journal of Pharmacological and Toxicological Methods, Vol. 61, No. 2 (March-April 2010), pp. 127135, ISSN 1056-8719.

Förster, T. (1948). Zwischenmolekulare Energiewanderung und Fluoreszenz. Annalen der Physik, Vol. 437, No.1-2. pp. 55-75. ISSN 1521-3889.

Grube, D. (2004) Constants and variables in immunohistochemistry. Archives of Histology and Cytology, Vol. 67, No. 2 (June 2004), pp. 115-134. ISSN 0914-9465.

Izant, J.G. \& McIntosh, J.R. (1980). Microtubule-associated proteins: a monoclonal antibody to MAP2 binds to differentiated neurons. Proceedings of the National Academy of Sciences of the USA, Vol. 77, No.8 (August 1980), pp. 4741-4745, ISSN 0027-8424.

Kenworthy, A.K. (2001). Imaging protein-protein interactions using fluorescence resonance energy transfer microscopy. Methods, Vol. 24, No. 3 (July 2001). pp. 289-296, ISSN 1046-2023. 
Kobrinsky, E., Stevens, L., Kazmi, Y., Wray, D. \& Soldatov, N.M. (2006). Molecular rearrangements of the Kv2.1 potassium channel termini associated with voltage gating. The Journal of Biological Chemistry, Vol. 281, No. 28 (July 2006), pp. 1923319240, ISSN 0021-9258.

Misonou, H., Menegola, M., Buchwalder, L., Park, E.W., Meredith, A., Rhodes, K.J., Aldrich, R.W. \& Trimmer, J.S. (2006). Immunolocalization of the Ca2+-activated K+ channel Slo1 in axons and nerve terminals of mammalian brain and cultured neurons. The Journal of Comparative Neurology, Vol. 496, No. 3 (May 2006), pp. 289-302, ISSN 10969861.

Mohapatra, D.P., Siino, D.F. \& Trimmer, J.S. (2008). Interdomain cytoplasmic interactions govern the intracellular trafficking, gating, and modulation of the Kv2.1 channel. The Journal of Neuroscience, Vol. 28, No. 19 (May 2008), pp. 4982-4994, ISSN 02706474 .

Mu, F.T., Callaghan, J.M., Steele-Mortimer, O., Stenmark, H., Parton, R.G., Campbell, P.L., McCluskey, J., Yeo, J.P., Tock, E.P. \& Toh, B.H. (1995). EEA1, an early endosomeassociated protein. EEA1 is a conserved alpha-helical peripheral membrane protein flanked by cysteine "fingers" and contains a calmodulin-binding IQ motif. The Journal of Biological Chemistry, Vol. 270, No. 22 (June 1995), pp. 13503-13511, ISSN 0021-9258.

Nagai, T., Sawano, A., Park, E.S. \& Miyawaki, A. (2001). Circularly permuted green fluorescent proteins engineered to sense Ca2+. Proceedings of the National Academy of Sciences of the USA, Vol. 98, No. 6 (March 2001), pp. 3197-3202, ISSN 0027-8424.

Nakamura, N., Rabouille, C., Watson, R., Nilsson, T., Hui, N., Slusarewicz, P., Kries, T.E. \& Warren, G. (1995). Characterization of a cis-Glogi matrix protein, GM130. The Journal of Cell Biology, Vol. 131, No. 6 pt. 2 (December 1995), pp. 1715-1726, ISSN 0021-9525.

Naumann, U., Cameroni, E., Pruenster, M., Mahabaleshwar, H., Raz, E., Zerwes, H.G., Rot, A. \& Thelen M. (2010). CXCR7 functions as a scavenger for CXCL12 and CXCL11. PLoS One, Vol. 5, No. 2 (February 2010), pp. e9175.

Ogawa, Y., Horresh, I., Trimmer, J.S., Bredt, D.S., Peles, E., \& Rasband, M.N. (2008). Postsynaptic density-93 clusters Kv1 channels at axon initial segments independently of Caspr2. The Journal of Neuroscience, Vol. 28, No. 22 (May 2008), pp. 5731-5739, ISSN 0270-6474.

Ortiz de Montellano P.R., David S.K., Ator, M.A., \& Tew, D. (1988). Mechanism-based inactivation of horseradish peroxidase by sodium azide. Formation of mesoazidoprotoporphyrin IX. Biochemistry, Vol. 27, No. 15 (July 1988), pp. 5470-5476, ISSN 0006-2960.

Ottschytsch, N., Raes, A., Van Hoorick, D. \& Snyders, D.J. (2002). Obligatory heterotetramerization of three previously uncharacterized $\mathrm{Kv}$ channel alphasubunits identified in the human genome. Proceedings of the National Academy of Sciences of the USA, Vol. 99, No. 12 (June 2002), pp. 7986-7991, ISSN 0027-8424.

Pollok, B.A. \& Heim, R. (1999). Using GFP in FRET-based applications. Trends in Cell Biology, Vol. 9, No. 2 (February 1999), pp. 57-60, 0962-8924. 
Raff, M.C., Fields, K.L., Hakomori, S.I., Mirsky, R., Pruss, R.M. \& Winter, J. (1979). Cell-typespecific markers for distinguishing and studying neurons and the major classes of glial cells in culture. Brain Research, Vol. 174, No. 2 (October 1979), pp.283-308, ISSN 0006-8993.

Ramon y Cajal, S., (1995). Histology of the Nervous System of Man and Vertebrates (History of Neuroscience, No 6). Oxford University Press, ISBN 978-0195074017, New York, New York.

Rhodes, K.J. \& Trimmer, J.S. (2006). Antibodies as valuable neuroscience research tools versus reagents of mass distraction. The Journal of Neuroscience, Vol. 26, No. 31 (August 2006), pp. 8017-8020, ISSN 0270-6474.

Rizutto, R., Brini, M., Pizzo, P., Murgia, M. \& Pozzan, T. (1995). Chimeric green fluorescent protein as a tool for visualizing subcellular organelles in living cells. Current Biology, Vol. 5, No. 6, (June 1995), pp. 635-642, ISSN 0960-9822.

Saper, C.B. (2005). An open letter to our readers on the use of antibodies. The Journal of Comparative Neurology, Vol. 493, No. 4 (December 2005), pp. 477-478, ISSN 10969861.

Scannevin, R.H., Murakoshi, H., Rhodes, K.J. \& Trimmer, J.S. (1996). Identification of a cytoplasmic domain important in the polarized expression and clustering of the Kv2.1 K+ channel. The Journal of Cell Biology, Vol. 135, No. 6, Part 1 (December 1996), pp. 1619-1632, ISSN 0021-9525.

Shi, S.R., Cote, R.J. \& Taylor, C.R. (2001). Antigen retrieval techniques: current perspectives. The Journal of Histochemistry and Cytochemistry, Vol. 49, No. 8, (August 2001), pp. 931-937, ISSN 0022-1554.

Spector, D.L. \& Goldman, R.D. (Eds.). (2006). Basic methods in Microscopy: Protocols and Concepts from Cells: A Laboratory Manual. Cold Spring Harbor Laboratory Press, ISBN 087969751-2, Cold Spring Harbor, New York.

Vacher, H., Mohapatra, D.P. \& Trimmer, J.S. (2008). Localization and targeting of voltagedependent ion channels in mammalian central neurons. Physiological Reviews, Vol. 88, No. 4 (October 2008), pp. 1407-1447, ISSN 0031-9333.

van Duijnhoven, M.W., van de Kerkhof, P.C., Pasch, M.C., Muys, L. \& van Erp, P.E. (2005). The combination of the Zenon labeling technique and microscopic image analysis to study cell populations in normal and psoriatic epidermis. Journal of Cutaneous Pathology, Vol. 32, No. 3 (March 2005), pp. 212-219, ISSN 1600-0560.

Van Zuylen, J. (1981). The microscopes of Antoni van Leeuwenhoek. Journal of Microscopy, Vol. 121, No. 3 (March 1981), pp. 309-328, ISSN 0022-2720.

Volk, T. \& Geiger, B. (1984). A 135-kd membrane protein of intercellular adherens junctions. EMBO J, Vol. 3, No. 10 (October 1984), pp. 2249-2260, ISSN 0261-4189.

Wada, I., Rindress, D., Cameron, P.H., Ou, W.J., Doherty, J.J. 2nd, Louvard, D., Bell, A.W., Dignard, D., Thomas, D.Y. \& Bergeron, J.J. (1991). SSR alpha and associated calnexin are major calcium binding proteins of the endoplasmic reticulum membrane. The Journal of Biological Chemistry, Vol. 266, No. 29 (October 1991), pp. 19599-19610, ISSN 0021-9258. 
Williams, J.H., Mepham, B.L. \& Wright, D.H. (1997). Tissue preparation for immunocytochemistry. Journal of Clinical Pathology, Vol. 50, No. 5, (May 1997), pp. 422-428, ISSN 0021-9746.

Yus-Nájera, E., Muñoz, A., Salvador, N., Jensen, B.S., Rasmussen, H.B., \& Defelipe, J., Villarroel, A. (2003). Localization of KCNQ5 in the normal and epileptic human temporal neocortex and hippocampal formation. Neuroscience, Vol. 120, No. 2 (February 2003), pp. 353-364, ISSN 0306-4522. 


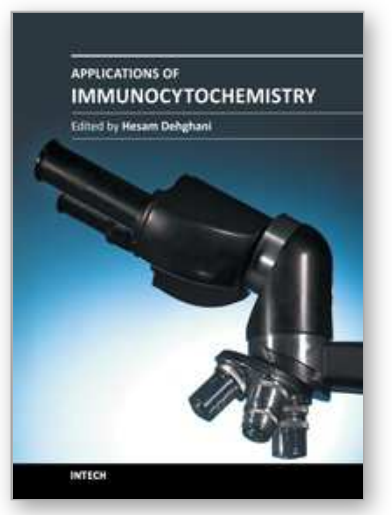

\author{
Applications of Immunocytochemistry \\ Edited by Dr. Hesam Dehghani
}

ISBN 978-953-51-0229-8

Hard cover, 320 pages

Publisher InTech

Published online 09, March, 2012

Published in print edition March, 2012

Immunocytochemistry is classically defined as a procedure to detect antigens in cellular contexts using antibodies. However, over the years many aspects of this procedure have evolved within a plethora of experimental setups. There are different ways to prepare a given specimen, different kinds of antibodies to apply, different techniques for imaging, and different methods of analyzing the data. In this book, various ways of performing each individual step of immunocytochemistry in different cellular contexts are exemplified and discussed. Applications of Immunocytochemistry offers technical and background information on different steps of immunocytochemistry and presents the application of this technique and its adaptations in cell lines, neural tissue, pancreatic tissue, sputum cells, sperm cells, preimplantation embryo, arabidopsis, fish gonads, and Leishmania.

\title{
How to reference
}

In order to correctly reference this scholarly work, feel free to copy and paste the following:

Elke Bocksteins, Andrew J. Shepherd, Durga P. Mohapatra and Dirk J. Snyders (2012). Immunostaining of Voltage-Gated Ion Channels in Cell Lines and Neurons - Key Concepts and Potential Pitfalls, Applications of Immunocytochemistry, Dr. Hesam Dehghani (Ed.), ISBN: 978-953-51-0229-8, InTech, Available from: http://www.intechopen.com/books/applications-of-immunocytochemistry/immunostaining-of-cell-lines-andneurons-key-concepts-and-potential-pitfalls

\section{INTECH}

open science | open minds

\section{InTech Europe}

University Campus STeP Ri

Slavka Krautzeka 83/A

51000 Rijeka, Croatia

Phone: +385 (51) 770447

Fax: +385 (51) 686166

www.intechopen.com

\section{InTech China}

Unit 405, Office Block, Hotel Equatorial Shanghai

No.65, Yan An Road (West), Shanghai, 200040, China

中国上海市延安西路65号上海国际贵都大饭店办公楼 405 单元

Phone: +86-21-62489820

Fax: $+86-21-62489821$ 
(C) 2012 The Author(s). Licensee IntechOpen. This is an open access article distributed under the terms of the Creative Commons Attribution 3.0 License, which permits unrestricted use, distribution, and reproduction in any medium, provided the original work is properly cited. 